\title{
Productivity Driven by Job Satisfaction, Physical Work Environment, Management Support and Job Autonomy
}

\section{Kyle Shobe*}

Department of Finance and General Business, Missouri State University, USA

\begin{abstract}
Business is driven by the necessity of building profits and adding to the value stream of the global economy. Every business across the globe looks to be highly productive and extremely lean and efficient. High productivity has many driving factors and those factors will be dissected and thoroughly examined to determine their effectiveness in altering productivity in the workplace. The research conducted shows the importance of being able to balance job satisfaction, ergonomics of the physical workplace, management support, and autonomy of the workforce to build a productive work environment. The research showed that job satisfaction correlates heavily with job performance and work output of staff. The physical work environment and how it affects productivity was researched and gave strong signs the two are related in many ways. Also, management support, as well as autonomy of the workforce proved to be leading factors in determining the level of productivity in the workplace. Through research and literature review, dissatisfied employees, poor working conditions, unsupportive management and alienation among team members drives poor performance and low productivity. In conclusion of the research on this topic, there will be a study done to help in supporting the literature findings. There was a survey conducted with one hundred office employees of a manufacturing plant which gives evidence and insight as to what variables really drive high productivity in the workplace.
\end{abstract}

Keywords: Management; Ergonomics; Autonomy

\section{Introduction}

\section{Topic of study}

The topics of study are based on high productivity as it relates to job satisfaction, ergonomics of the physical workplace, management support and autonomy.

\section{Background}

Office work has been around for thousands of years, and has grown with mankind from early periods of time with the formation of social culture, economics, political organizations and state administrations. Dating back to before the 19th century, office work took the form of state administration type activities [1]. These forms then evolved and during the industrial revolution, and the invention of the steam engine, the industrialized office emerged. The industrial civilization of the 19th century would grow and become what is known today as the beginning of administration buildings, headquarters of companies, and research and development facilities. Early into the 20th century and post-industrial period, many people turned from industry type work to data transmission type work and the majority of office personnel were focusing on the scientific and technological areas [1]. In the 21st century the office space and workers are built around being agile and focused on change. The workplace is designed to convey messages to staff and visitors, and the office space must show the importance of work culture and values of the organization. The office should be a hub for bringing work partners together for networking, mentoring, collaborating and knowledge sharing, all while being able to attract and retain top talent [2].

In recent history, the working conditions of the office were quite different than they are today. For instance, high productivity would be thought of as almost impossible in the early 1970s, where there were electronic typewriters, dial phones with cords, no internet, wireless networks, and people were allowed to smoke in the office [3]. Fast forward to 2017, and many, if not all, of the aforementioned things are different. However, it is not to say that in the 1970s, the ideas of what is known today weren't around. Computers were being developed and new office layout concepts were being thought of by companies such as IBM. IBM engineers had ideas of increasing productivity through the use of telecommuting and the removal of permanent work stations [3]. Present day has working conditions that must accommodate at least 4 generations of people, meaning that many of the office environments must account for the demands from the different age groups. These demands could include, meeting spaces, special lighting and acoustic elements, and demands for accommodations for vision, hearing, posture, mental health and weight [2].

The demands for productivity were also alive and well, task autonomy was developing and the majority of the fortune 1000 companies were enabling their employees in the ideas of empowerment and self-management and to become autonomous in the early 1990s [4]. Langfred [4] found that these ideas of autonomy increased dramatically in 1993 and practically every large company in the United States were practicing forms of autonomy, or at least were considering the use of autonomy to allow for increased job satisfaction among employees, as well as increased productivity. Before the successful implementation of job autonomy in the majority of the large companies, hierarchical control existed. This type of control would drive employees to suppress the mechanisms within themselves which would normally regulate their ideas and thoughts of improvements and turns it over to the higher power [5]. Those individuals would then suppress there independent functionality and autonomy to fit into the hierarchical organization.

*Corresponding author: Shobe K, Department of Finance and General Business, Missouri State University, USA, Tel: + 417-836-5000; E-mail: climberup@gmail.com

Received April 05, 2017; Accepted May 02, 2018; Published May 09, 2018

Citation: Shobe K (2018) Productivity Driven by Job Satisfaction, Physical Work Environment, Management Support and Job Autonomy. Bus Eco J 9: 351. doi: 10.4172/2151-6219.1000351

Copyright: (c) 2018 Shobe K. This is an open-access article distributed under the terms of the Creative Commons Attribution License, which permits unrestricted use, distribution, and reproduction in any medium, provided the original author and source are credited. 
This ideology would eventually be removed from the workplace due to the harmful effects it had on productivity and morale.

In the year 1911, Frederick Taylor's Principles of Scientific Management grew from the premise that employees had to be monitored and supervised closely and that the people were motivated by economics and fair wages despite the harsh working environments and micromanagement [6]. Contrary to Taylor's principles, Singh [6] discussed the outcome of Elton Mayo and his colleagues studies by saying they determined in 1933, that increases in performance were related to employee's social environments and the attention they received from management. The importance of the study really drew attention to the significance of the psychological factors affecting the motivation and productivity of employees, which included autonomy, group cohesiveness and attention to social factors.

\section{Problem Statement}

Many organizations demand employees to be highly productive and efficient. The organizations need to first understand the pressure points and how to push the employees to be productive. There is a real problem in the world today with driving employees to be productive without over-burdening them with unhealthy amounts of work, which will eventually cause them to be unproductive and possibly disgruntled. Therefore, it is necessary to dive into what drives productivity and research how job satisfaction, physical working environment, management support and job autonomy play a role in creating a productive workplace. Herzberg, a great leader of motivational studies of humans insists that having a good salary and safe work setting is not enough to constitute a significant and sustaining work incentive, yet it requires content factors such as a captivating and purposeful meaning of work, liability, and for others to recognize the work completed [7].

\section{Literature Review}

The literature review is designed to explain and develop the different variables which were researched. The dependent variable, high productivity, as well as the four independent variables, job satisfaction, physical work environment (ergonomics), management support, autonomy, will be deeply researched and understood before the testing of these variables is completed. This will allow the researcher to build a strong foundation for comprehension of the complete study.

\section{Productivity}

Productivity is crucial in business offices and can be driven by factors such as job satisfaction, physical working environment, management support and autonomy within the workforce. Firms must recognize the capacity of their intellectual capital and utilize it to the fullest whenever possible. Intellectual capital can be recognized as the contributions from the human capital of an organization [8]. This human capital can also be categorized as a form of intangible assets for an organization which can be considered roughly $80 \%$ of a firm's total value. The above mentioned factors which determine the effectiveness and efficiency of the work force and the productive atmosphere. Productivity is a product of how satisfied the employees are with their work, and typically the more satisfied they are with their work the more productive they are, and vice versa.

The correct balancing of employee mental satisfaction to social, economic and psychological effects allows for the employee to become comfortable and conducive to good spirits, motivation, high morale and higher productivity [9]. It is the balancing of those factors which allows for the employee to feel comfortable in their surroundings.
Productivity can also be considered as one's job performance, with job performance it states it involves the behavior and action taken by the employee. The employee's job performance is related to the individual's ability to perform his or her job and their satisfaction of job performance grows as their abilities and confidence grows [10]. Siengthai and PilaNgarm [10] go on to say with that many of the employees which have the same level of productivity over time plateau and lose the willingness to be productive in the same job, therefore it is important to design jobs which have little room to plateau and drive the employee to learn new things and remain satisfied and productive.

More than fifty percent of the world's population works in an office environment and many of the features of the office determine the level of productivity within that space [11]. With that being said, Fassoulis and Alexopoulos [12] also noted that job satisfaction and productivity are largely affected by the actual physical workplace. The key to higher productivity is being able to make the office operations within an environment which provides a nice comfortable place to work; this in turn provides an environment which maintains an optimal level of productivity [13]. The issue of sound levels in buildings have been proven to cause for low or high levels of productivity. For instance a study done by Mak and Lui [14], who studied 259 office workers in Hong Kong proved that the effects of sound, temperature, and office layout had a strong correlation with productivity levels. They went on to show evidence of reduced productivity levels from the basic annoying office sounds of ringing phones, conversation and machines. In their study it also indicated human activity, such as closing doors, background noise and noises form both inside and outside of the office proved to be distracting to the workforce and reducing productivity. Investment in lighting for the office not only improves the electricity bill but, is also proven to increase productivity in the workforce and give employees a safer environment to work [15]. Higher productivity is a result of the ability to work optimally in your environment and to feed off the synergies of the surrounding employees. This promotes the creativity which is needed for the motivations of all employees to be productive and an active component of the business [12].

Productivity in the workplace can be simply created by managers and their ability to lead and make good examples out of themselves, as well as making good examples out of others. Managers should encourage every employee to be innovative and should concentrate on showing support by quickly adopting employees' ideas, as well as show appreciation for employees who convey ideas forward [16]. The core factor of success in most organization is a productive workforce. Many times this comes with management style and how best to handle the workforce to become and stay productive. The studies of Matin et al. [17] conclude the importance of a stress free and engaged workforce. Their studies show the importance of managers understanding their workforce and making sure the workforce coveys a message to management on what makes them the most productive. Also the use of stress management by the managers will alleviate any additional stress which may be brought on by increased workloads [17]. Productivity can be impacted by many things, both good and bad, however, collaboration and team building activities if done correctly can have a big impact on overall productivity. With that being said, Fourie and Fourie [18] have stated that when implemented correctly through management styles, collaboration can cut the time it takes to complete a task. There is however a large risk with collaboration being used that with poor management implements the strategies it can lead to longer times to complete the task at hand. Therefore it is crucial for management to implement the processes and strategies to allow for increases in productivity. 
Productive employees tend to desire and look for reasons to become more productive in nature, and with that find that becoming more autonomous or empowered will drive them to become more productive. Langfred [4] also found this to be true and states that there is a strong relationship between employees wanting to participate in decision making and being in control of what they feel is necessary to do at a particular point in time, and therefore find that productivity is driven by the self-managed spirit of the employee to become autonomous. Sales people are driven to promote and sell products for the company they are employed by and many times there are strict rules by management which does not allow the employee to be highly productive. Therefore, it is important for people in certain industries to have a high degree of autonomy so they are able to being highly productive individuals [19]. The same holds true for nurses within hospitals; they are continuously taking care of patients and having to make decisions on what to do in a split second of time. It is important to understand the performance of their job is reliant upon the jurisdiction of their job. This is also considered to be the amount of autonomy they are able to have. Penny [20] supports the idea that nurses show they are more productive in giving care and patient safety is much higher when they have a feeling of self-efficacy and autonomy. Autonomy then leads to feeling of empowerment and engagement within the field of nursing and really starts to show effects of positive productivity levels [20].

\section{Job satisfaction}

Job satisfaction and productivity is at the forefront of interest for employers and it is important to understand the benefits of job satisfaction and what it means. People spend the majority of their lives at work than any other place, it is important that the place they spend the majority of their adult life is one that they are satisfied [21]. When the individual is happy the company is happy and many good things happen when this is the case, including increases in productivity, creativity, quality, customer satisfaction, innovation, and adaptation. Labour markets and economists should really understand the significance of job satisfaction, it has been documented to have high positive correlations with worker performance and productivity [22]. Difficult working conditions cause for workers to be dissatisfied and overburdened with an abundance of workload. Increases in monetary rewards are not fully replacing the need for satisfaction in the work area, but more so, human to human interactions and relationships drive the overall satisfaction [23]. According to Antoni et al. [24], they concluded when monetary rewards are distributed evenly across the team it would tend to increase morale and productivity among the group. However, when the rewards were handed out based on performance it tended to extrude deviant behaviour between team members driven by the individual competiveness for the monetary reward. Therefore, monetary rewards can be misleading and hurt performance if not fully understood the effects of the program.

Employee's satisfaction with their job is important in driving growth and increases in productivity. The human resources of an organization are generally the best resource the organization has, it is the main resource which makes a company perform or not perform. Banga [25] states it very strongly by saying, people are the life of the organization and the productivity of all other resources within the organization depend on the productivity of the human resources employed with that company. The meaning of job satisfaction is important to understand when it comes to the satisfaction of a workforce and the perceived productivity of the particular workforce. With that being said, job satisfaction as defined by Saranya [26], is the extent to which the person's job fulfills his or hers dominant need and is then consistent with their expectations and values. If these criteria are met the person will find their job to be satisfying. Job satisfaction according to Siddiqui [27], also states the importance of five specific dimensions which include, the work itself, pay, promotion, superintendence/associates, and opportunities. It is important to point out what exactly job satisfaction correlates with, it can be associated with job involvement, turnover, job performance, absenteeism, organizational commitment, life satisfaction, motivation, organizational citizenship behaviour, perceived stress and mental health [28].

The industrial environment strives for production and satisfied workers, this is because satisfied workers produce more and allow for a relatively smooth and conductive work environment [26]. The issue revolving around the studies done on job satisfaction is the issue of it meaning something different to each individual in a specific situation. For instance, job satisfaction could be altered by situations in an individual's life, it is possible the individual had to deal with an unchallenging job, not receiving feedback concerning performance, lack of recognition for job done, lack of necessary tools to complete job, poor communication, and lastly, lack of available training or development activities [27]. Many times these show to be determining factors in whether or not an employee is happy with the work they do. It is possible that the happiest employee is unsatisfied with their job, due to the fact the job is not meeting the internal forces of beliefs, interests, feelings and actions which generates the level of job satisfaction one would need [29]. Most individuals desire a level of satisfaction with what they are doing and this leads to either a productive or nonproductive individual.

Herzberg played a big role in the study of job satisfaction and what caused people to be either satisfied or dissatisfied with their work. He developed a two-factor theory, which consisted of motivators and hygiene factors and these two topics would help explain job satisfaction in the workplace [30]. Herzberg used the motivators as a means to show factors which could actually affect the satisfaction, whereas the hygiene factors could not make the employee more satisfied it just kept the employee from becoming dissatisfied with their job [31]. In other words, Herzberg's motivating factors will cause for psychological growth and cause for someone to have high job satisfaction, but the absence of these motivators will not necessarily cause dissatisfaction. Hygiene factors do not cause the individual to become satisfied with their job, however the absence of these factors will cause job dissatisfaction [32]. An employee is motivated by the motivator factors and the alterations to the hygiene factors and with that it allows the employee to become less discontent, but it does not make them more motivated or more productive [7]. It is important to understand what is described as being a motivating factor according to Herzberg, motivating factors are associated with achievement, supervisor's empathy and caring, the opportunity for growth, relevant work, and supervisor recognition of achievement [30]. Costello and Welch [30] also give an understanding of the hygiene factors according to Herzberg, hygiene factors are associated with policies and administration, interpersonal relationships, and supervision practices. These sets of motivators and hygiene factors work together uniquely to allow for effective performance of each employee. For instance, an employee will not change and become more productive if motivating factors are not present, as well as an employee will not put forth the effort at a job if the hygiene factors have not been met [31].

Job satisfaction is extremely important when it comes to people willing to stay at their current employer. People with high levels of job satisfaction tend to be more productive and hold positive attitudes, the 
opposite is true for people who are dissatisfied, and they are looking for other jobs with higher involvement and with that, higher satisfaction [9]. Jobs which consist of higher job involvement tend to drive higher satisfaction for that particular person. Job dissatisfaction can be turned around through the ability to redesign and implement change to specific individual which have been performing the same job for multiple years. With job redesign the ability establishes motivational potential is quite promising and has the ability to enrich the job and boost satisfaction for the employee [10]. Siengthai and Pila-Ngarm [10] go on to explain that job characteristics which include variety, control, feedback and autonomy seem to drive the majority of positivity towards job satisfaction. The more interesting an employee's job is every day the more likely the job will produce a satisfied worker and with that significant increases in job productivity.

One of the worst, if not the worst thing an organization could do to the individual working for them is to create interference between the employee and his or her family, this can motivate the employee to feel unimportant to the organization and lead to a low commitment level and poor productivity [33]. Employees having the ability to have an alternative work schedule increases their satisfaction with work related tasks because they are able to have equal or a comfortable amount of time from the workplace. This in turn, relieves the stresses and anxieties of work getting in the way of their personal lives and matters which reside outside of work. If they have the ability to leave work at a more flexible time then individuals are able to be more productive and tend to show a stronger commitment towards the organization [34]. The key to having a good work life/balance is to create a schedule which is somewhat easy to keep and one which does not take away from the managers ideas of what should be completed each day.

\section{Ergonomics/physical working environment}

The physical working environment is crucial in driving workers job satisfaction and productivity [35]. Many studies are based on the physical environment and its impact on the human resources of the company as it relates to things such as, lighting, aesthetics of interior spaces and noise levels [12]. Poor work conditions drive higher costs and decrease the performance of the organization leading to lower productivity and higher costs [36]. Research performed by Abdul [23], revealed that when these poor conditions increased they added stress to the work environment and in turn lead to unbearable workloads and higher turnover. This was also made evident by Fassoulis and Alexopoulos [12], stating the same result, that a poor work environment has not only proven reduction in job satisfaction and productivity, but also increases in absenteeism, depression, burnout, musculoskeletal disorders and so on.

Distraction in the work environment plays a large role in whether someone is productive or not. The ability to go through work without being distracted leads to effective collaboration and productivity [37]. De Been and Beijer [37] go on to say that the office layout and how people are situated among one another also plays a role in the level of productivity in the workplace. The design of the office layout drives the possibilities of becoming distracted by both noise levels, as well as foot traffic in the office. An interesting study was done to go one step further and determine if office space decoration affected productivity or not. The study revealed some interesting results, it showed when an office space is decorated in the manner the employee found to be desirable, they were more productive. The study even made it clear when employees were put in control of the decoration of the offices they were more empowered and productive [38].
The idea of a clean and obstruction free work surface came to light in the 18th century by a guy named Josiah Wedgwood and he believed the workplace must be clear of any and all interferences which were not helping to complete the task. Centuries later in 1911, Frederick Taylor also had a concept of organizational space management and ideas of keeping the workplace clean and free of distractions in hopes it would create a productive environment [39]. Going beyond 1911 and into the late 20th century research has shown these early philosophies of bare workplaces to be disadvantageous to productivity. The lean philosophy was driven to keep the workspace of the individual to eliminate waste, allowing for the employee to stay focused on the work task and not on the personalization of their workspace [38]. There are advantages to a workplace with some decor and especially living plants which can add to the health of the environment both physically and mentally [39].

The introduction of plants into the workplace was the next big step in transforming a once sterile environment into a productive and healthy workplace. Nieuwenhuis et al. [39], further explain the importance of having a green work environment, by saying the introduction of plants into the office space would drive a more efficient work environment, as well as the plants make the office space more collaborative and humane. The interesting fact about plants in the workplace is derived from the health impacts, as well as the productivity impacts. Gray and Birrell [40] discuss this topic in depth and find the presence of plants in the work place as beneficial in many ways. The plants offer as a resource of improving indoor air quality and they can also promote well-being, significantly increasing employee morale and improvements in staff performance.

There is reason for large concern for managers when it comes to the overall status of their employee's well-being. Working in an indoor environment which is not healthy can be associated with employee's poor health, morale, absenteeism, and productivity [41]. Krishnamoorthy et al. [41] developed research to find the existence of what is known as sick building syndrome (SBS) and this is a direct side effect of poor indoor working environments. These poor indoor working environments cause SBS and will in turn hurt overall productivity in the workspace if left untreated. Researchers have found improvements in indoor environments will reduce depression, stress perceived absenteeism and will show improvements in productivity [41]. This increasingly draws awareness to the importance of having living plants in the workplace. Not only will it increase productivity, it will improve the well-being of the employees [39].

Research shows physical working environments have direct correlations with job satisfaction and organizational performance with tests showing there is a strong relationship between employees being satisfied at work and high productivity because of favorable work environment [35]. Noise levels in the office space can cause for distraction and decreased levels of productivity. This also strengthens the argument that there is a direct correlation between the physical working environments layout and productivity [36]. Workplace environments have been key influencing factors when it comes to satisfaction and productivity. Many times productivity can be determined by factors such as personalization, colour, privacy, interior painting, lighting, windows, air quality, temperature, noise levels and accessibility [13]. Khamkanya et al. [13] go on to say, improvements in the overall office environment can drive an increase in productivity by almost 15 percent. This proves the importance of the physical workplace's environment and the support it needs from management. Management is the main factor which must be involved in the design and layout of people and desks to result in the highest level of productivity. 
Many of the workplaces today are focusing on collaboration and open office areas. These open office areas drive collaboration but, also may drive less area for concentrated work. Harris [2] agrees with the fact that open office workplaces need the ability to be open and allow for collaboration, but also agrees there is a need for concentration space as well, which will then promote and satisfy the ability to remain productive. Productivity relies on the ability of an office environment to allow for people to move around and collaborate with other colleagues. Just as Buckley et al. [42] researched, open office environments promote standing and moving away from the desk which also promotes productivity, collaboration and is overall healthier for the employee. Sedentary working positions cause for many health issues and with sitstand adjustable desks available for employees, this issue of sedentary work is less of an issue and in the end promotes collaboration and productivity [42]. The working environment has significant effects on productivity of the workforce.

\section{Management support}

Leadership is a vital part in the productivity of a team and or organization. Overall higher management involvement is directly and positively linked to higher labour productivity, quality and financial performance [43]. Transformational leaders who are able to challenge budgets, engage effectively with the workforce, consider and figure out new ways of working are on the right path for improving productivity. If those same leaders go one step further and invest in the appropriate advanced training then they will have a highly trained and productive workforce [44]. Business leaders need to look into their current group of employees, as well as themselves and understand who is strong at what task. The management should gather intelligence of their own people to appropriately allocate the human capital across the organization to gain the most productive group possible [45]. The ability to allocate human capital across the organization based on those particular employee strengths is something a transformational leader would be able to do. Transformational leaders have the ability to consider individuals on their team as a person with their own abilities and they are able to see the individual's strengths and weaknesses to best allocate them to a role, making them the most productive possible [46]. Choi et al. [46] elaborated on transformational leaders by saying they are also able to in still pride and respect to their employees, motivate and enrich their spirit and vision in both individual and organizational parts of the business and lastly, encourage non-traditional thinking to see new ways of completing tasks or solving problems. Transformational leadership is largely linked to employee engagement and also keeps employees aware of essential matters which will allow them to see things with new perspectives [47]. Unfortunately, many leaders in business lack the ability to have long-term business goals or aspirations and have a hard time with finding the long-term vision of their business or team. In addition to the lack of long-term visions, most leaders have an even more difficult time involving their team in any vision, which causes for hardship and lack of productivity [45]. This goes into the ideas of leadership and the relationship they have with their followers. When a leader is considered to be a good fit in the follower's eyes, then this means the followers are willing and more likely to perform at a higher level than if the relationship was opposite [48].

Employee engagement is defined by Abraham [49] as being the commitment level of the employees of the company to the business strategies and goes beyond the point of job satisfaction, it touches on aspects of pride and advocacy about the company's products and brands. Employee engagement is driven by the management of the employees by allowing them to be fully engaged in the company and its products or services. It is important that management gives employees opportunities to learn and grow with the company, this in-turn will engage the employee and drive true productivity [50]. Leadership is a leading factor when it comes to motivating employees to become engaged in their work. This is because the behaviour of the leader works as a source of motivation and satisfaction for individuals, and it is that motivation which drives them to become engaged and a productive member of the organization [46]. The leadership should have a strong determination to engage employees and drive productivity up, this is evident by research conducted by Radda et al. [51] who stated that due to the engagement gap of the United States workforce, it had cost businesses roughly three hundred billion dollars annually because of the consequential production loss due to lack of employee engagement. The engagement level of employees worldwide is lower than $50 \%$, which means productivity levels are well below their potential. Management must engage and support employee's interests and strengths to gain back lost productivity. Transformational leadership can guide employees into truly believing they are fully engaged and they then exhibit levels of emotional, physical, and cognitive aspects leading to organizational success and high amounts of productivity [47]. The ability to provide positive feedback is also a way to engage the employee and make them feel as part of a team. This is confirmed by the research conducted by Stasishyn and Ivanov [5], when they found employees which received feedback from there management they were more motivated to give the manager ideas on how to make operations better and how they could be more productive. It also promoted the ability for the teams to work together and support each other.

Management is able to engage the employee and support the employee in much of what they do to create productivity, but it is also important the manager of the office is able to create an environment which allows for management to measure and monitor the employees, attitude, motivation, and opinions. This will give the employees the ability to create an environment rich in building relationships of honesty, trust and integrity [9]. Management skills in allowing for fruitful communications between human and human interactions is growing in significance in the current era of management support topics to grow both employee satisfaction and productivity [23]. Abdul [23] revealed, the influence management have on their employees as being satisfied with the work they have done and the work they are going to do.

Managers have to give their employees more freedom when it comes to the jurisdiction at their place of employment. Mangers should not create rigid operating procedures which stifle the ability for employees to be creative and innovative when doing work related tasks. If management allows for employees to have freedom of how to do their job, it will lead to job satisfaction, other organization advantages, as in low turnover, low absenteeism and will improve productivity [16].

Research has been completed to link the management style of giving monetary rewards to employees for outstanding achievements or performance based pay, however, it has shown to be both beneficial and detrimental. Therefore, it is management's responsibility to introduce a pay-for-performance (pfp) scale which allows for employees to remain satisfied and in the end become more productive [24]. Management also needs to have the ability to manage the levels of success and target set for each individual employee. Management also needs to be able to regulate the stress levels of their employees and understand that their actions can directly affect an employee's willingness to perform. Martin et al. [52] points out four important broad themes of behavior for managers to follow. These themes include, respect and responsibility, 
communicating and managing existing and future work, managing the employee within the team, and lastly reasoning and managing difficult situations. These four themes when implemented effectively will successfully avoid stress among employees of a department or team and drive the team to higher levels of productivity and stress management.

\section{Autonomy}

Autonomy within a work group is important to have and it bears a certain kind of responsibility. Autonomy is considered a crucial part of many jobs and is defined as the total amount of discretion and or freedom one has in carrying out their assigned job [4]. Responsible autonomy mixes both individual and group responsibility all while the individuals of the group are all interdependent on their team, each other and the entire cycle of operations. Individuals have shared responsibility in meeting goals and demands of the work they are doing, all while contributing to the development of work on an individual and intergroup level [53]. Employee loyalty and autonomy on the job seems to be directly linked, meaning the increase in autonomy for the employee drives an increase in employee loyalty and with that, a chance for increased performance and mental health on the job. This in turn, gives employees more freedom as to how and when their job gets done and drives additional loyalty towards the supervisor or organization [54].

Job autonomy in work scheduling is very important to certain groups of people and allows for them to be productive at different times of the day. Employees which have the ability to have a flexible work schedule were much more likely to report a happy medium between work life and family life [34]. This is most importantly true when it comes to parents with obligations which force them to leave work early for family conflicts. Work schedule autonomy allows for the parents to leave work early and then go back to work later to finish a job. Higher work schedule autonomy among parents showed to improve job satisfaction and productivity at work [55]. Karasek and Theorell's Demand/Control model for autonomy and control is crucial to one's own work life and is of great importance when it comes to the psychosocial environment and the learning abilities of the organizations and individuals [53]. Flexible work hours a great example of how autonomy can help out families with their work life/balance, which so many people desire in today's activity infused world. Work life/balance can be defined as the ability to balance simultaneously the emotional, temporal and behavioral demands work and family responsibilities [34]. This difficult balance of personal life and work life can turn into a stress induced life which results in poor performance at work and unhappy family members.

Autonomy is not a new phenomenon, however it is growing with importance in the current business era and has been focusing on the effects it has on productivity over the past decade. Task autonomy is the freedom an employee has to do the tasks of their day to day job and generally it is linked to results having to do with increased motivation, satisfaction and performance [4]. Autonomy is different for each area of business and for employees of companies which do not have their manager nearby may find themselves with a perception of autonomy. For instance, a salesperson has little interaction face to face with their manager, however many times the manager gives the salesperson strict rules limiting their autonomy, and this then reduces the ability for the salesperson to perform losing sales productivity [19]. Pettijohn et al. [19] went on to say that the large majority of salespersons which are allowed to have full autonomy tend to be more productive and also raise the levels of customer service. Autonomy also gives internal entrepreneurs the ability to achieve results through the need to make important choices and the need to have resources to facilitate the creative process to improve the performance and exploit opportunities for the organization [56]

The ability for employees to craft and design their own jobs is at the heart of job autonomy. Mobile workers in the UK find that they are thirteen percent more productive than the office-based employees. Working remotely promotes a self-managed atmosphere which drives higher productivity [57]. Autonomy and job crafting are one in the same, job crafting is a conceptualized view of the ability of one person to design their job the most strategic way possible, which is turn should allow for the person to have better job performance [58]. Autonomy is a motivator and can drive people to take more ownership of the tasks they work on. Eventually the act of allowing to people to autonomous in the workplace will allow them to become more engaged in their work and push them to be more satisfied and productive [6]. Singh [6] provides insight to the importance of autonomy by saying it is possible the sense of autonomy will have a powerful effect on the individual and increase their performance level in the workplace. Nursing is a good example of what kind of job would require a high sense of autonomy. Penny [20] confirms the importance of autonomy and nurses being productive and happy with the jobs they do. She goes on to point out that with the autonomy being focused on, the employee will be more committed to the organizational outcomes.

\section{Methodology}

\section{Participants}

There will be roughly 100 full time salaried employees randomly surveyed at a manufacturing plant. The total population of the plant is roughly 650 full time salaried employees which have jobs ranging from finance, purchasing, sales, IT, quality and engineering. The sample size of 100 will be targeted to answer a questionnaire which will be sent out at random to employees from the main population. The researcher will omit employees which are not in an office setting due to the relevance of the questionnaire. The participants in the survey will range in age from 22 to 60, and will have all different levels of experience in the field. The participants will also be diversified in nationality, culture and gender. Participants in the survey will be both male and female. The participants will be selected out of the total population at random. The random selection will be based on a complete list of participant email addresses. These will be loaded into a survey type system which will automatically be sent to the selected participants. The participants will be anonymous to the researcher and the researcher will not know the gender, nationality or any other forms of information about the participant. This will allow for the population as a whole to be studied by the randomly selected group of participants.

\section{Questionnaire design}

The questionnaire is designed in a way to have consistent, clear and concise questions which allow for the participant to move easily through the questions and to guide them in a way to understand what is being asked of them. There will be a total of 25 questions which test each independent variable and the dependent variable. This allows the participant to have some consistency within the questionnaire and may lead to higher quality results. Each variable has a scale which was used to accurately gather detail which may relate the independent variables to the dependent variable. The goal was to have high levels of significance for each independent variable to the dependent variable.

The first set of questions have to do with the dependent variable which is productivity and what drives the participant to be productive 
at their place of work. The questions have been reviewed by Dr. Mustapha and have been selectively tested on a small sample size of people to see the internal consistency of the questions. They use a scale which was developed based on other questionnaires with the same scale of $1=$ strongly disagree to $5=$ strongly agree. The questions were designed to flow and grab the participant's attention with being consistent in nature. The questions start the same which should allow the participant to concentrate on the questions being asked. Refer to Table A1 in the Appendix A. The above questions are designed to determine what really drives productivity in the workplace and who the leading factor of that drive and motivation is. These questions however, can be answered completely different from person to person. The reason for this is that each person has a job which can be very much different from one another. Each individual participant will have portions of job satisfaction, physical work environments, managerial support and autonomy being driving factors of their productivity. This issue of questions being answered differently will be limited by using the correct sample size group and the correct participants within the group.

The second set of questions involve job satisfaction and what makes the participants satisfied at work. The idea is to find an understanding of what really drives the happiness in the workplace. Depending on the level of satisfaction, productivity can be affected. This portion of the questionnaire will utilize the five-point Likert scale of $1=$ being very dissatisfied to $5=$ Very Satisfied [12]. The questions are derived from an already proven and tested scale of the Minnesota Satisfaction Questionnaire (MSQ) [59]. This instrument has been peered reviewed and tested locally with a small sample size (10-15 people). The MSQ has a Cronbach Alpha of 0.86 . The questions were taken from the short form of the original questionnaire. Refer to Table A2 in the Appendix A [60]. These questions are meant to provide feedback to the researcher to see how satisfied people generally are at work and from that, conclusions can be made with regards to its effect on productivity.

The third set of questions involves the physical work environment and what may affect the productivity of each participant. The questions have been reviewed by Dr. Mustapha and have been selectively tested on a small sample size of people to see the internal consistency of the questions. They use a scale which was developed based on other questionnaires with the same scale of $1=$ strongly disagree to $5=$ strongly agree. The questions in the below table are being used to determine if the physical environment plays a role in productivity of employees [6164]. Refer to Table A3 in the Appendix A. The questions were designed to effectively determine if employees of the office environment are affected by changes in the physical work environment or how the physical work environment is set up. These questions are directly designed to ask office employees of the sample group being tested. People whom do not work in an office setting may skew the data being collected. This portion of the questionnaire will allow for the research which has already been completed to be either supported or not supported when it comes to effects of the physical work environment on productivity of employees [65].

The fourth set of questions involves the importance of management support and how it may affect the productivity level of employees with an office setting. The questions have been reviewed by Dr. Mustapha and have been selectively tested on a small sample size of people to see the internal consistency of the questions. They use a scale which was developed based on other questionnaires with the same scale of $1=$ strongly disagree to $5=$ strongly agree. The general idea of the set of questions below is to grasp the importance of a manager being involved in the employees work. Management can drive productivity within their employees if they are able to connect with them and engage them in the business strategies and product brand. Therefore, the questions below are designed to see if participants are supported and engaged by their management. Refer to Table A4 in the Appendix A. The outcome of the questions above will support the research within the literature review with details on if office employees truly feel important and involved [66]. If employees feel strongly about being important in the work they do, the research within the literature review and this questionnaire can then determine that management support does increase and improve productivity within a specific workgroup.

The fifth and final set of questions revolves around job autonomy. The questions in this section of the survey are developed from using a scale which has been designed to capture the significance of job autonomy. The instrument which was used is called James Breaugh's instrument for work autonomy scales. This instruments was a Cronbach Alpha of 0.915. The questions were chosen based on the relationship they may have with the dependent variable researched which is productivity. The questions for job autonomy are in the figure below. Refer to Table A5 in the Appendix A. The list of questions for job autonomy will give good insight to the importance of job roles and autonomy for personnel.

\section{Result and Conclusion}

The data collected and the paired literature review will be able to show the importance of job autonomy and its apparent effects on productivity.

\section{References}

1. Niezabitowska $E$ Winnicka-Jaslowska $D$ (2011) Evolution of the office building in the course of the 20th century: Towards an intelligent building. Intelligent Buildings International 3: 238-249.

2. Harris R (2015) The changing nature of the workplace and the future of office space. Journal of Property Investment \& Finance 33: 424-435.

3. Juriaan VM (2011) The origins of new ways of working. Facilities 29: 357-367.

4. Langfred CW (2013) To be or not to be autonomous: Exploring why employees want more autonomy. North American Journal of Psychology 15: 355-366.

5. Stasishyn S, Ivanov S (2013) Organization Derobotized: Innovation and Productivity in a Workplace Environment. International Journal of Organizational Innovation 5: 45-51.

6. Singh R (2016) The impact of intrinsic and extrinsic motivators on employee engagement in information organizations. Journal of Education for Library and Information Science 57: 197-206.

7. Lazaroiu G (2015) Work Motivation and Organizational Behavior. Contemporary Readings in Law and Social Justice 7: 66-75.

8. Phusavat K, Comepa N, Sitko-Lutek A, Keng-Boon O (2013) Productivity management: Integrating the intellectual capital. Industrial Management \& Data Systems 113: 840-855

9. Jha AK, Dikshit S (2015) Employee satisfaction: A comparative study between tata steel and central coalfield limited, ranchi. Anusandhanika 7: 111-119.

10. Siengthai S, Pila-Ngarm $P$ (2016) The interaction effect of job redesign and job satisfaction on employee performance. Evidence - Based HRM 4: 162-180.

11. Vimalanathan K, Thangavelu RB (2014) The effect of indoor office environment on the work performance, health and well-being of office workers. Journal of Environmental Health Science \& Engineering.

12. Fassoulis K, Alexopoulos $\mathrm{N}$ (2015) The workplace as a factor of job satisfaction and productivity. Journal of Facilities Management 13: 332-349.

13. Khamkanya T, Heaney G, McGreal S (2012) Introduction of AHP satisfaction index for workplace environments. Journal of Corporate Real Estate 14: 80-93.

14. Mak CM, Lui YP (2012) The effect of sound on office productivity. Building Services Engineering Research \& Technology 33: 339-345. 
Citation: Shobe K (2018) Productivity Driven by Job Satisfaction, Physical Work Environment, Management Support and Job Autonomy. Bus Eco J 9: 351. doi: 10.4172/2151-6219.1000351

Page 8 of 9

15. Osibanjo AO, Gberevbie DE, Adeniji AA, Oludayo AO (2015) Relationship modeling between work environment, employee productivity, and supervision in the Nigerian public sector. American Journal of Management 15: 9-23.

16. Sungkhawan J, Mujtaba BG, Swaidan Z, Kaweevisultrakul T (2012) Intrapreneurial workplaces and job satisfaction: The case of thai employees. Journal of Applied Business Research 28: 527-542.

17. Matin HZ, Razavi HR, Emamgholizadeh S (2014) Is stress management related to workforce productivity? Iranian Journal of Management Studies 7: 1-19.

18. Fourie I, Fourie H (2013) Getting it done on time. Library Hi Tech 31: 391-400.

19. Pettijohn CE, Schaefer AD, Burnett MS (2014) Salesperson Performance: Exploring the Roles of Role Ambiguity, Autonomy and Self-Efficacy. Academy of Marketing Studies Journal 18: 99-111.

20. Penny $H$ (2014) Healthy work environment framework within an acute care setting. Journal of Theory Construction \& Testing 18: 50-54.

21. Duari P, Sia SK (2013) Importance of happiness at workplace. Indian Journal of Positive Psychology 4: 453-456.

22. Tumen S, Zeydanli T (2016) Social interactions in job satisfaction. Internationa Journal of Manpower 37: 426-455.

23. Abdul R (2013) Impact of Working Environment on Job Satisfaction. 2nd Global Conference on Business, Economics, Management and Tourism, Czech Republic.

24. Antoni CH, Baeten X, Perkins SJ, Shaw JD, Vartiainen M (2017) Reward management: Linking employee motivation and organizational performance. Journal of Personnel Psychology 16: 57-60.

25. Banga S (2012) A comparative Study of Factors Affecting Employee Satisfaction with reference to Public and Private Sector Banks. International Journal of Management Research and Reviews 2: 1831-1837.

26. Saranya K (2014) Influence of job satisfaction on employees' performance - A general perspective. International Journal on Global Business Management \& Research 2: 48-53.

27. Siddiqui NN (2015) An Empirical Study on Job Satisfaction among Faculties in Selected Personal Universities Of Uttar Pradesh. International Journal of Management Research and Reviews 5: 238-245

28. Maamari BE (2014) Changing management history, gender moderating pay to job satisfaction for IS users. Journal of Management History 20: 311-332.

29. Awan WA (2013) Determinants of shift work impacting job satisfaction: A study on service sector organizations in pakistan. International Journal of Research in Business and Social Science 2: 49-59.

30. Costello R, Welch SA (2014) A Qualitative Analysis of Faculty and Studen Perceptions of Effective Online Class Communities Using Herzberg's MotivatorHygiene Factors. Quarterly Review of Distance Education 15: 15-23.

31. Vijayakumar VSR, Saxena U (2015) Herzberg revisited: Dimensionality and structural invariance of herzberg's two factor model. Journal of the Indian Academy of Applied Psychology 41: 291-298.

32. Keogh $P$ (2013) Motivation for grant writing among academic librarians. New Library World 114: 151-165

33. Devi AC, Rani SS (2012) Personality and work - life balance. Journal of Contemporary Research in Management 7: 23-30.

34. Wadsworth LL, Facer RL (2016) Work-family balance and alternative work schedules. Public Personnel Management 45: 382-404.

35. Ashraf MS, Bashir M, Bilal MY, ljaz K, Usman M (2013) The impact of working environment on organization performance: A mediating role employee's job satisfaction. Global Management Journal for Academic \& Corporate Studies 3 $131-150$

36. Panchanatham N, Jayalakshmi V (2016) A study on employee safety and workplace hazards in relation to performance of jewellery manufacturing industries. Journal of Contemporary Research in Management 11: 1-9.

37. De Been I, Beijer M (2014) The influence of office type on satisfaction and perceived productivity support. Journal of Facilities Management 12: 142-157.

38. Greenaway KH, Thai HA, Haslam SA, Murphy SC (2016) Spaces that signal identity improve workplace productivity. Journal of Personnel Psychology 15 $35-43$.
39. Nieuwenhuis M, Knight C, Postmes T, Haslam SA (2014) The relative benefits of green versus lean office space: Three field experiments. Journal of Experimental Psychology Applied 20: 199-214.

40. Gray T, Birrell C (2014) Are biophilic-designed site office buildings linked to health benefits and high performing occupants? International Journal of Environmental Research and Public Health 11: 04-22.

41. Krishnamoorthy A, Kronenburg MA, Shetterly DR, Gaillard F (2016) Exploring the Relationship between Indoor Work Environment and Employee Perception of Health-Related Symptoms in an Office Environment. International Journal of Management Research and Reviews 6: 44-58

42. Buckley JP, Hedge A, Yates T, Copeland RJ, Loosemore M, et al. (2015) The sedentary office: An expert statement on the growing case for change towards better health and productivity. British Journal of Sports Medicine 49: 1357.

43. Bushra A, Masood M (2017) The impact of organizational capabilities on organizational performance: Empirical evidence from banking industry of Pakistan. Pakistan Journal of Commerce and Social Sciences 11: 408-438.

44. Thompson J (2012) Transformational leadership can improve workforce competencies. Nursing Management 18: 21-24.

45. Denton A (2013) Why is productivity falling in 2013 ? The role of leadership in creating growth during the recession. Strategic Direction 29: 3-5.

46. Choi SB, Kim K, Kang S (2017) Effects of Transformational and Shared Leadership Styles on Employees Perception of Team Effectiveness. Social Behavior and Personality 45: 377-386.

47. Mozammel S, Haan P (2016) Transformational Leadership and Employee Engagement in the Banking Sector in Bangladesh. The Journal of Developing Areas 50: 43-55

48. Soane E, Butler C, Stanton E (2015) Followers' personality, transformational leadership and performance. Sport, Business and Management 5: 65-78.

49. Abraham S (2012) Development of employee engagement programme on the basis of employee satisfaction survey. Journal of Economic Development, Management, IT, Finance, and Marketing 4: 27-37.

50. Choi SB, Tran TBH, Park BI (2015) Inclusive Leadership and Work Engagement Mediating Roles of Affective Organizational Commitment and Creativity. Socia Behavior and Personality 43: 931-943.

51. Radda AA, Majidadi MA, Akanno SN (2015) Employee Engagement: The New Model of Leadership. Indian Journal of Management Science 5: 17-26.

52. Martin CA (2005) From high maintenance to high productivity: What managers need to know about generation $\mathrm{Y}$. Industrial and Commercial Training 37: $39-44$

53. Enehaug H (2017) Ten successful years: A longitudinal case study of autonomy, control and learning. Nordic Journal of Working Life Studies 7: 67-89.

54. Linz S, Good LK, Busch M (2015) Promoting worker loyalty: An empirical analysis. International Journal of Manpower 36: 169-191.

55. Nadler JT, Voyles EC, Cocke H, Lowery MR (2016) Gender disparity in pay, work schedule autonomy and job satisfaction at higher education levels. North American Journal of Psychology 18: 623-642.

56. Felício JA, Rodrigues R, Caldeirinha V (2012) The effect of entrapreneurship on corporate performance. Management Decision 50: 1717-1738.

57. Crunden N (2016) Help mobile workers feel less remote. Occupational Health \& Wellbeing. 68: 11 .

58. Demerouti E, Bakker AB, Halbesleben JRB (2015) Productive and counterproductive job crafting: A daily diary study. Journal of Occupational Health Psychology 20: 457-469.

59. Minnesota Satisfaction Questionnaire (2017)

60. Baldry C (1997) The social construction of office space. International Labour Review 136: 365-378

61. Dinibutun SR (2012) Work motivation: Theoretical framework. GSTF Business Review 1: 133-139.

62. Dutta N, Koepp GA, Stovitz SD, Levine JA, Pereira MA (2014) Using sit-stand workstations to decrease sedentary time in office workers: A randomized crossover trial. International Journal of Environmental Research and Public Health 11: 6653-6665. 
Citation: Shobe K (2018) Productivity Driven by Job Satisfaction, Physical Work Environment, Management Support and Job Autonomy. Bus Eco J 9: 351. doi: 10.4172/2151-6219.1000351

Page 9 of 9

63. Maurya MK, Agarwal M (2015) Relationship between supportive leadership, mental health status and job satisfaction of civil police constables. Journal of the Indian Academy of Applied Psychology 41: 103-111.

64. Tariq Q, Kanwal F (2012) Relationship of job satisfaction with self actualization: Pakistan's organizational perspective. Indian Journal of Positive Psychology 3: $374-377$.
65. Woestman DS, Wasonga TA (2015) Destructive leadership behaviors and workplace attitudes in schools. National Association of Secondary Schoo Principals Bulletin 99: 147-163.

66. Waymer RW (1995) A study of work autonomy and job satisfication of social workers in Metropolotan Atlanta. 